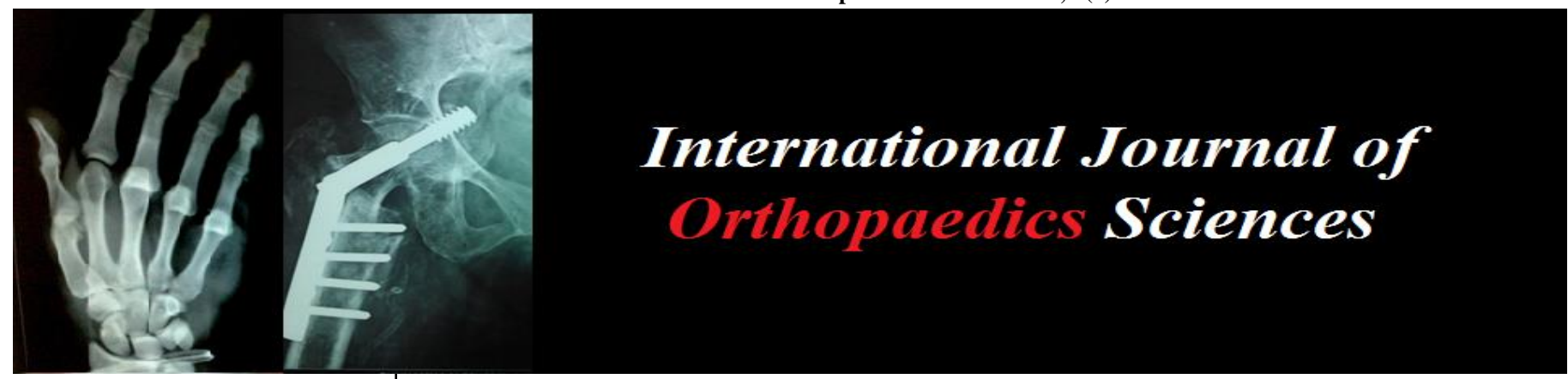

ISSN: $2395-1958$

IJOS 2019; 5(1): 497-499

(C) 2019 IJOS

www.orthopaper.com

Received: 16-11-2018

Accepted: 20-12-2018

Dr. Mayur Rai

A.J Institute of Medical Science

\& Research Centre, Mangalore,

Karnataka, India

Dr. Shetty Suraj Ravindra

A.J Institute of Medical Sciences

\& Research Centre, Mangalore,

Karnataka, India
Correspondence

Dr. Mayur Rai

A.J Institute of Medical Sciences

\& Research Centre, Mangalore,

Karnataka, India

\section{Non-ossifying fibroma of the radius: A rare case report}

\author{
Dr. Mayur Rai and Dr. Shetty Suraj Ravindra
}

DOI: https://doi.org/10.22271/ortho.2019.v5.i1i.87

\section{Abstract}

The non-ossifying fibroma (NOF) is a benign, non-neoplastic lesion most commonly seen in the metaphyses of the long bones in children. While rare, the NOF has been reported in the radius as well. Radiographically, it is well delineated multi or uniloculated lesions with sclerotic margins. It is commonly found in children and adolescents and is the most common fibrous bony lesion. Therefore, it is important to recognize the clinical and radiographic characteristics of this benign lesion.

Keywords: Non-ossifying fibroma, non-neoplastic, metaphyses

\section{Introduction}

The non-ossifying fibroma (NOF) was first recognized by Sontag and Pyle around $1941^{[1]}$. The following year, Jaffe and Lichtenstein formally identified the lesion and termed it the "non-osteogenic fibroma of bone ${ }^{[2]}$. The NOF is classified as a tumor-like lesion grouped according to the histologic classification of bone tumors by the World Health Organization (WHO) ${ }^{[3,4]}$. A number of synonyms for the NOF have been used which are descriptive and reflect the natural evolution of the lesion. These names include histiocytic fibrous defect, metaphyseal fibrous defect, fibrous cortical defect ${ }^{[5]}$, fibrous xanthoma and histiocytic xanthogranuloma ${ }^{[6]}$.

Currently, the two most frequently used terms to describe these lesions are the "fibrous cortical defect" (FCD) and the "non-ossifying fibroma" (NOF) ${ }^{[7]}$. The FCD and the NOF are the most common benign lesions of the skeletal system ${ }^{[1,8]}$, arising most frequently in the metaphyseal region of the distal femur, proximal and distal tibia and fibula in children and adolescents ${ }^{[9]}$. Radiographic studies in the orthopaedic literature have shown that $33 \%$ of otherwise normal children have one or more small fibrous cortical defects ${ }^{[1]}$.

\section{Case Report}

An 18 year old male patient, student by profession had an alleged history of fall on an outstretched hand while playing kabaddi following which he complained of pain in the left forearm. Following fall he was taken to a local hospital in Kasargod where X-ray was taken and was said to have a fracture (Figure 1). Above elbow slab was applied, analgesics were given and he was referred to a higher centre in Mangalore. One week later he came to our hospital for further management where a repeat x-ray was taken (Figure 2 and 3). On admission MRI of the left forearm (Plain and contrast) was done for further evaluation which showed enhancing expansile cortico-medullary lesion in the diaphysis of radius associated with pathological fracture of shaft of radius suggestive of benign bone tumour (Figure 4). Patient was posted for surgery on the following day. Left radius curettage and bone grafting with open reduction and internal fixation with plating was done (Figure 5 and 6). The curetted bone was sent for histopathology. The bony bits measured $1.6 \mathrm{X} 1 \mathrm{X} 0.5 \mathrm{~cm}$. The sections showed bony trabeculae, dense fibrous tissue along with numerous proliferating capillaries and large areas of haemorrhage. Periphery showed reactive bone transformation with osteoblast rimming along with multinucleate giant cells suggesting a non-ossifying fibroma (Figures 7, 8, 9).

Patient was discharged on the fifth post operative day. Sutures were removed two weeks post operatively. After 3 weeks, above elbow slab was removed and above elbow cast was put. The cast was removed after 3 weeks and physiotherapy in the form of elbow ROM exercises and pronation and supination exercises were initiated. 
At the final follow up of three months, patient had satisfactory results and was able to carry out his daily activities without difficulty and final radiographs showed good fracture healing.

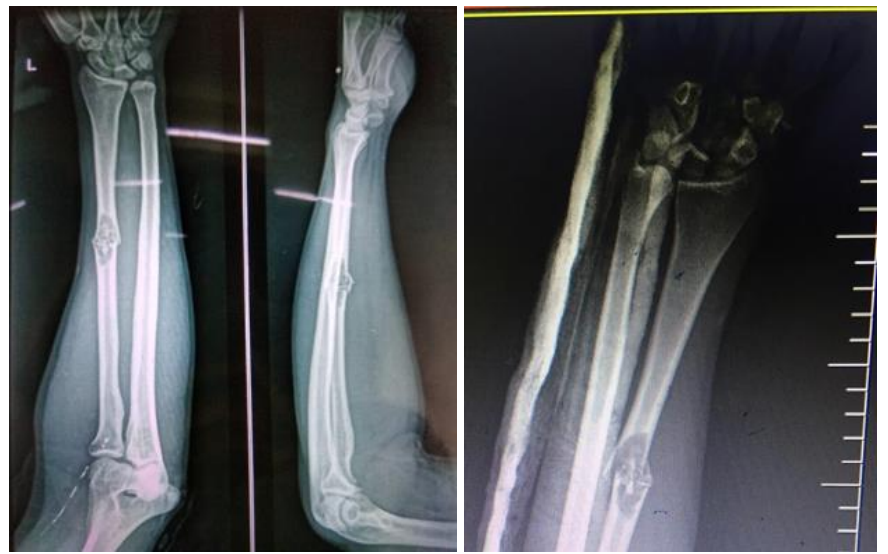

Fig 1: Pre-op xray Fig 2: After slab application- AP view

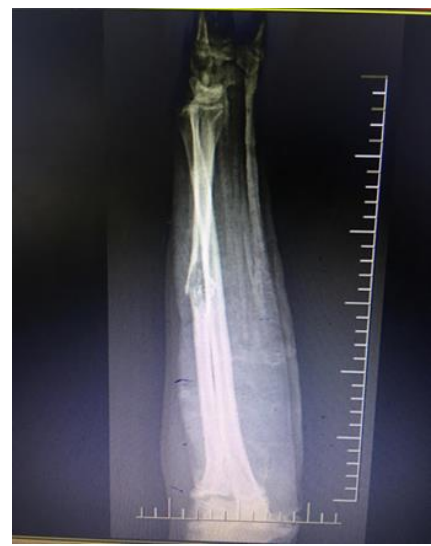

Fig 3: After slab application lateral view

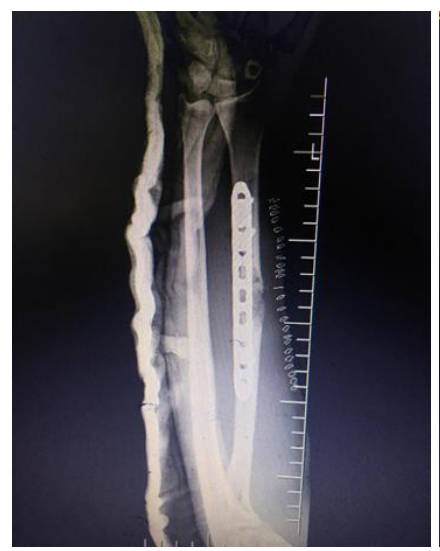

Fig 5: Post op xray-A Pview

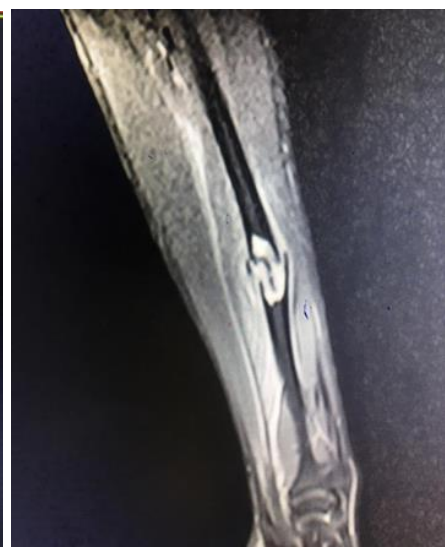

Fig 4: MRI image showing lesion

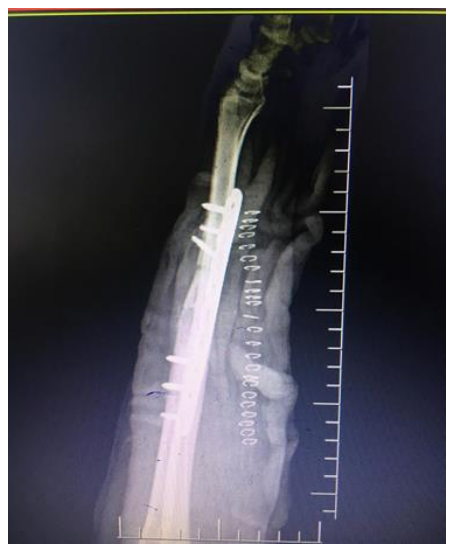

Fig 6: Post op xray-lateral view

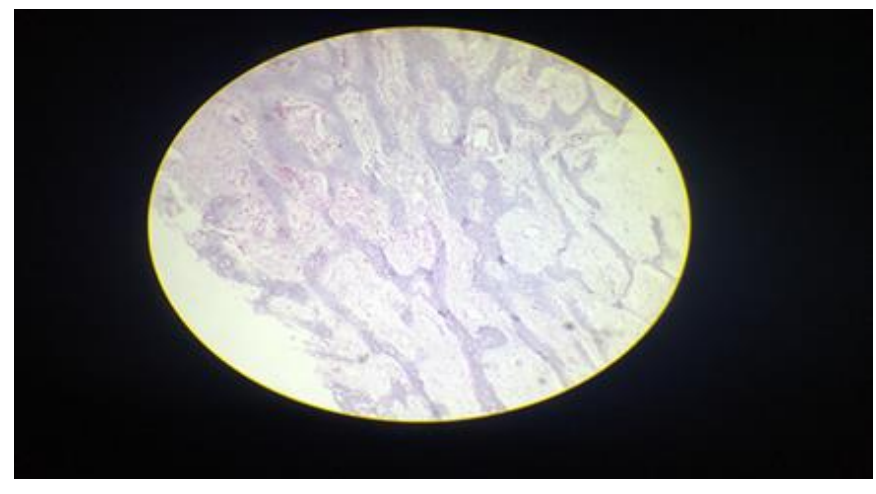

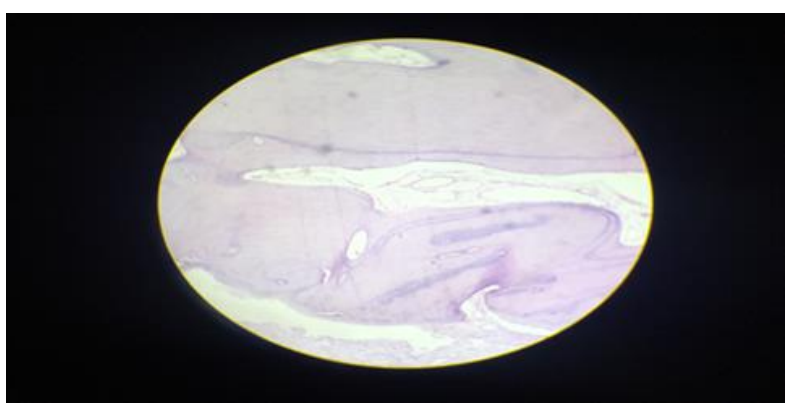

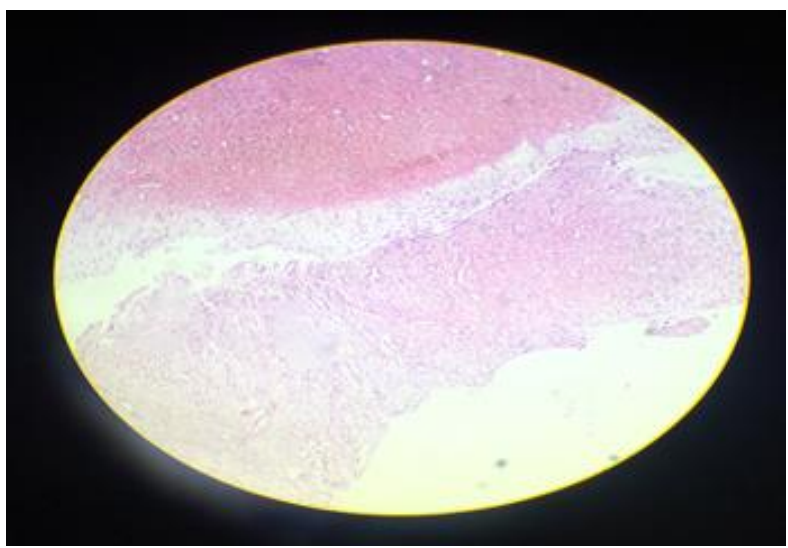

Fig 7, 8, 9: Histopathology slides

\section{Discussion}

The main entity that is often included in the histologic differential diagnosis of NOF is the Focal Cortical Dysplasia (FCD). The FCD is a small, lytic, intracortical lesion found in children. It is typically eccentrically located and sharply outlined and represents an osteolytic defect with a thin shell of reactive bone. Generally, because of their small size, FCDs are asymptomatic and are likely to undergo spontaneous regression. Occasionally, the FCD will enlarge, become progressively more separated from the growth plate and extend into the medullary cavity ${ }^{[6]}$. While the NOF and the FCD refer to the same histopathological process, the NOF is distinguished from the FCD by its larger size $(3 \mathrm{~cm})$ and extension from the cortex into the medullary cavity ${ }^{[2,10]}$.

While the majority of NOFs are asymptomatic, those that are particularly large may cause chronic pain and/or pathologic fracture in the long bones ${ }^{[11,12]}$. Diagnosis of NOF in the long bones is based upon the characteristic radiographic and clinical appearance, typically the NOF appears as an asymptomatic multiloculated lesion often identified incidentally during radiographic evaluation indicated for another reason ${ }^{[1,11,12]}$.

When arising in a large, tubular bone, the NOF is always eccentric and ovoid and often results in thinning and expansion of the overlying cortex. There is usually no periosteal reaction ${ }^{[13]}$ and no overt violation of the cortex ${ }^{[14]}$. While the clinical and radiographic features are pathognomonic for the NOF in the long bones ${ }^{[13]}$, the rarity of this lesion in the mandible makes preoperative diagnosis unlikely. Therefore correlation of the histopathologic features with the radiographic and clinical presentation is imperative. There are reports of NOF in the long bones with clonal rearrangements in chromosomes $1,3,4,11$, and 14. The presence of clonal chromosomal changes may suggest genetic events associated with tumorigenesis in the reported NOFs. Further study is required to determine whether there are 
consistent karyotypic aberrations associated with the $\mathrm{NOF}^{[12]}$. Histologically, the NOF consists of spindle-celled fibrous tissue in a storiform pattern with a variable number of multinucleated giant cells, hemosiderin pigment within fibroblasts, and lipid-laden histiocytes (xanthoma cells) ${ }^{[3,4]}$.

\section{Association with Jaffe-Campanacci Syndrome}

Patients with Jaffe-Campanacci syndrome (disseminated multiple NOF in association with cafe -au-lait spots, mental retardation, hypogonadism, and congenital ocular or cardiac anomalies) often have mandibular lesions of $\mathrm{NOF}^{[5,15,16]}$. Campanacci et al. ${ }^{[17]}$ hypothesized that this syndrome may represent an atypical presentation of neurofibromatosis. The lesions of NOF in the long bones in this syndrome are reported to be more aggressive with a higher rate of associated pathologic fracture and resolution of the lesions at the completion of skeletal maturity ${ }^{[15]}$.

\section{Conclusion}

In conclusion, nonossifying fibromas are the most common fibrous bony lesion found usually in metaphysis of long bones like femur, tibia and fibula and rarely found in diaphysis of radius and therefore, it is very important to recognize and suspect the clinical and radiographic characteristics of this benign lesion in radius also and treat accordingly.

\section{References}

1. Sontag LW, Pyle DI. The appearance and nature of cystlike areas in distal femoral metaphyses of children. Am J Roentgenol Radiat Ther. 1941; 46:185-8.

2. Jaffe HL, Lichtenstein L. Non-osteogenic fibroma of bone. Am J Pathol. 1942; 18:205-20.

3. Schajowicz F, Ackerman LV, Sissons HA et al. International histological classification of tumors (histological typing of bone tumors). Geneva: World Health Organization, 1993.

4. Mizukawa N, Nishijima Y, Nishijima K. Metaphyseal fibrous defect (non-ossifying fibroma) in the mandible. A case report. Int J Oral Maxillofac Surg. 1997; 26:129-30.

5. Chrcanovic B, Albanese AL, Freire-Maia B et al. Nonossifying fibroma (metaphyseal fibrous defect) of the mandible. Oral Maxillofac Surg. 2011; 4:233-7.

6. Fletcher CDM, Unni KK, Mertens F. World Health Organization: classification of tumours. Pathology and genetics of tumours of soft tissue and bone. Lyon: IARC Press, 2002.

7. Dahlin DC. Fibroma (nonosteogenic fibroma of bone, metaphyseal fibrous defect), myxoma, cortical desmoid, fibromatosis, and "Xanthoma". In: Thomas CC, editor. Bone tumors. General aspects and data on 6,221 cases, 3rd ed. Springfield, IL: Charles C Thomas, 1978, 122-36.

8. Betsy M, Kupersmith LM, Springfield DS. Metaphyseal fibrous defects. J Am Acad Orthop Surg. 2004; 12:89-95.

9. Glockenberg A, Sobel E, Noel JF. Nonossifying fibroma. Four cases and review of the literature. J Am Podiatr Med Assoc. 1997; 87(2):66-9.

10. Blau RA, Zwick DL, Westphal RA. Multiple nonossifying fibromas. A case report. J Bone Joint Surg Am. 1988; 70:299-304.

11. Shaffer LG, Tommerup N. editors. ISCN: an international system for human cytogenetic nomenclature. Basel: S. Karger, 2005.

12. Brassesco MS, Valera ET, Engel EE et al. Clonal complex chromosome aberration in non-ossifying fibroma. Pediatr Blood Cancer. 2010; 54:764-7.
13. Blau RA, Zwick DL, Westphal RA. Multiple nonossifying fibromas. A case report. J Bone Joint Surg Am. 1988; 70:299-304.

14. Hudson JW, Livesay KW, McCoy JM. Condylar lesion. J Oral Maxillofac Surg. 2003; 61:824-6.

15. Bailey JS, Nikitakis NG, Lopes M et al. Non-ossifying fibroma of the mandible in a 6-year-old girl: a case report and review of the literature. J Oral Maxillofac Surg. 2001; 59:815-8.

16. Hamada $\mathrm{T}$, Ito $\mathrm{H}$, Araki $\mathrm{Y}$ et al. Benign fibrous histiocytoma of the femur: review of three cases. Skeletal Radiol. 1996; 25:25-9.

17. Campanacci M, Laus M, Boriani S. Multiple nonossifying fibromata with extraskeletal anomalies: a new syndrome? J Bone Joint Surg Br. 1983; 65:627-32. 